\title{
UNIFORMLY STABLE SOLUTION OF A NONLOCAL PROBLEM OF COUPLED SYSTEM OF DIFFERENTIAL EQUATIONS
}

\author{
A.M.A El-Sayed, R.O. AbD-El-Rahman And M. El-Gendy
}

Abstract. In this paper we are concerned with a nonlocal problem of a coupled system of differential equations. We study the local existence of the solution and its continuous dependence. The global existence and its uniform stability is being studied.

Mathematics subject classification (2010): 34B18, 34B10.

Keywords and phrases: coupled systems, nonlocal conditions, local existence, global existence, continuous dependence, stability.

\section{REFERENCES}

[1] A. Boucherif AND R. PRecup, On the nonlocal initial value problem for first order differential equations, Fixed Point Theory, 4, 2 (2003), 205-212.

[2] A. Boucherif, First-order differential inclusions with nonlocal initial conditions, Applied Mathematics Letters, 15 (2002), 409-414, doi:10.1016/S0893-9659(01)00151-3.

[3] A. BouCHERIF, Nonlocal Cauchy problems for first-order multivalued differential equations, Electronic Journal of Differential Equations, 2002, 47 (2002), 1-9.

[4] A. BoucherIF, Semilinear evolution inclusion with nonlocal conditions, Applied Mathematics Letters, 22 (2009), 1145-1149, doi:10.1016/j.aml.2008.10.004.

[5] L.BYSZEWSKI AND V.LAKSHMIKANTHAM, Theorem about the existence and uniqueness of a solution of a nonlocal abstract Cauchy problem in a Banach space, Applicable analysis, 40 (1991), 11-19, doi:10.1080/00036819008839989.

[6] A. M. A. El-S AYED AND SH. A. AbD El-S Alam, On the stability of a fractional-order differential equation with nonlocal initial condition, Electron. J. Qual. Theory Differ. Equ., 2008, 29, 8 p., (2008).

[7] A. M. A. EL-S AYED AND I. AMEEN, Continuation of a parameterized impulsive differential equation to an internal nonlocal Cauchy problem, Alexandria Journal of Mathematics, 2, 1 (2011).

[8] A. M. A. El-SAYED AND E. O. BIN-TAHER, A nonlocal problem for a multi-term fractional order differential equation, Int. J. Math. Anal., 5, 29 (2011), 1445-1451.

[9] A. M. A. El-S AYED AND E. O. Bin-TAHER, An arbitraty fractional order differential equation with internal nonlocal and integral conditions, Advances in Pure Mathematics, 1, 3 (2011), 59-62.

[10] A. M. A. El-SAYEd AND E. O. Bin-TAher, Positive nondecreasing solutions for a multi-term fractional-order functional differential equation with internal conditions, Electronic Journal of Differential Equations, 2011, 166 (2011), 1-8.

[11] A. M. A. EL-S AYED AND E. O. BIN-TAHER, A nonlocal problem of an arbitrary fractional ordes differential equation, Alexandria Journal of Mathematics, 1, 2 (2010).

[12] A. M. A. El-SAYED AND KH. W. ELKADEKY, Caratheodory theorem for a nonlocal problem of the differential equation, Alexandria Journal of Mathematics, 1, 2 (2010).

[13] A. M. A El-Sayed, E. M. Hamdallah And KH. W. ElKadeKy, Internal nonlocal and integral condition problems of the differential equation, J. Nonlinear Sci. Appl., 4, 3 (2011), 193-199.

[14] A. M. A. El-Sayed, E. M. Hamdallah and KH. W. Elkadeky, Uniformly stable positive monotonic solution of a nonlocal Cauchy problem, Advances in Pure Mathematics, 2, 2 (2012), 109 113, doi:10.4236/apm.2012.22015. 
[15] A. M. A El-SAyed, E. M. Hamdallah AND Kh. W. ElKadeKy, Solution of a class of deviatedadvanced nonlocal problems for the differential inclusion $x^{\prime}(t) \in F(t, x(t))$, Abstract and Applied Analysis, 2011 Article ID 476392, 9 p., (2011), doi:10.1155/2011/476392.

[16] E. Gatsori, S.K. NTOuYas And Y.G. SFiCAS, On a nonlocal Cauchy problem for differential inclusions, Abstract and Applied Analysis, 2004 (2004), 425-434, doi:10.1155/S108533750430610X.

[17] K. Goebel And W.A. Kirk, Topics in Metric Fixed Point Theory, Cambridge University Press, (1990), 243 pages.

[18] G. M. GuEREKATA, A Cauchy problem for some fractional abstract differential equation with nonlocal conditions, Nonlinear Analysis, 70 (2009), 1873-1876, doi:10.1016/j.na.2008.02.087.

[19] O. NICA, Initial-value problems for first-order differential systems with general nonlocal condition, Electronic Journal of Differential Equations, 2012, 74 (2012), 1-15. 